\section{Air pollution exposure and IPF: prevention when there is no cure}

\author{
Kerri A Johannson
}

The clinical management of idiopathic pulmonary fibrosis (IPF) is challenging. For patients with a progressive disease with no known cure, realistic goals include slowing the rate of disease progression, optimising comorbidities and functional status, managing symptoms, and preventing what is preventable. The latter is short however, mainly including smoking cessation and infection prevention measures. Despite adherence to recommended management, most patients deteriorate over time, with some experiencing acute exacerbation (AE), and the majority dying due to their IPF. ${ }^{1}$ Identifying modifiable risk factors that limit disease progression or death could change clinical practice, offering preventative tools with which to achieve the goal of improving patient quality and quantity of life.

Air pollution exposure is ubiquitous and a well-established risk factor for a wide range of adverse health outcomes including cardiovascular disease and all-cause mortality. ${ }^{2-4}$ Arguably the most common target is the respiratory system, given its exposure to the inhaled environment. Indeed, air pollution exposures are associated with increased risk of developing and exacerbating airway diseases, bronchiolitis obliterans post lung transplant, as well as being diagnosed with and dying from lung cancer. ${ }^{5-11}$ IPF was a relative latecomer to the world of air pollution epidemiology, although a number of plausible mechanisms exist to suggest a relationship. ${ }^{12}$ While it is unlikely that air pollution is the sole driver of disease, it may represent one form of environmental insult that precipitates or accelerates fibrosis in an already vulnerable lung.

In Thorax, Sesé and colleagues contribute novel data to a growing body of literature informing the risks of air pollution exposure in patients with IPF. ${ }^{13}$ They identified 192 incident patients from COFI (COhorte FIbrose), a prospective multicentre French cohort designed to characterise the natural history of IPF. Patients were assigned to

Correspondence to Dr Kerri A Johannson, Departments of Medicine \& Community Health Sciences, University of Calgary, 4448, Calgary AB T3M1M4, Canada; kerri.johannson@ahs.ca the air monitoring station closest to their residential address to estimate exposures to ground-level ozone $\left(\mathrm{O}_{3}\right)$, nitrogen dioxide $\left(\mathrm{NO}_{2}\right)$, and particulate matter less than $2.5 \mu \mathrm{m}$ and $10 \mu \mathrm{m}$ in aerodynamic diameter $\left(\mathrm{PM}_{2.5}\right.$ and $\mathrm{PM}_{10}$, respectively). Three clinical outcomes were assessed-AE, disease progression and all-cause mortality-using 6-week mean precedent exposures for AE-IPF, and mean exposure levels from enrolment to censoring for the latter two outcomes. Exposure to $\mathrm{O}_{3}$ was significantly associated with an increased risk of AE-IPF, while $\mathrm{PM}_{2.5}$ and $\mathrm{PM}_{10}$ exposures were significantly associated with mortality in this cohort. This is the first study to identify a relationship between air pollution exposure and mortality in patients with IPF, and their findings validate a prior report identifying $\mathrm{O}_{3}$ as a risk factor for AE-IPF, with similar effect sizes when comparable statistical analyses were used. ${ }^{14}$

To date only two other studies have investigated the relationship between air pollution and IPF, the first reporting an association between $\mathrm{O}_{3}$ and $\mathrm{NO}_{2}$ exposures and AE-IPF in a retrospective Korean cohort. ${ }^{14} \mathrm{~A}$ more recent study of 135 patients examined the impact of $\mathrm{PM}_{2.5}$ and $\mathrm{PM}_{10}$ on disease progression, defined by decline in FVC over follow-up time, finding accelerated FVC decline associated with increased $\mathrm{PM}_{10}$ exposure. ${ }^{15}$ They found no relationship between $\mathrm{PM}_{2.5}$ and FVC decline, nor between either exposure and mortality risk in that retrospective cohort. The current study by Sesé and colleagues is the largest and most comprehensive study on this issue to date, with a number of important strengths. ${ }^{13}$ They included a well-characterised prospective cohort with longitudinal outcomes assessment, and accessed a high density of air quality monitoring stations in the study area to enhance the accuracy of exposure measurements. Furthermore, they measured $\mathrm{PM}_{2.5}$ levels, an exposure with high biological plausibility to impact IPF, and an exposure that was not available in the prior Korean study. Their findings were consistent across sensitivity analyses and after adjustment for appropriate potential confounders.
The limitations of these data reflect the challenges of environmental epidemiology in a complex disease, and are not unique to the current study. Exposure misclassification is the greatest potential bias, as geospatial approaches using residential addresses may inaccurately estimate air pollution exposures. It is also unknown if local air quality measures reflect actual inhaled exposures and their biological impact. Improved accuracy in measures of exposure may require patients to wear portable air quality monitors or that biomarker measurements be incorporated to reflect physiological impact of exposure, neither widely available at the present time. The relationship between air pollution exposure and adverse health outcomes may be confounded by important socioeconomic variables, and these were not accounted for in the present study. Future work should delve further into the potential effect modification of genetics, social determinants or disease activity in determining the impact of air pollution on IPF.

One would be hard-pressed to imagine a scenario where air pollution exposure would be good. Nevertheless, studying the issue from a disease-specific framework is important for at least three reasons. First, these data inform the potential risks within a specific patient population. Patients with IPF, and possibly those with any form of fibrotic interstitial lung disease, should be considered a vulnerable population when interpreting air quality levels and making behavioural modification recommendations intended to mitigate their risks of exposure. Second, the recognition of these relationships may further inform the pathobiology of disease. It is generally recognised that alveolar epithelial injury is an important step along the pathway to IPF, although the causes of injury remain unclear and may differ between individuals. Air pollution exposure may represent one form of environmental catalyst driving aberrant wound healing in a genetically or otherwise susceptible individual. Further work to delineate these mechanisms is needed. Third, once a problem is identified, we can assess whether intervening might favourably alter outcomes, moving us from the realm of 'potentially' to 'a modifiable risk factor'.

It is unknown if personal face masks, high efficiency particulate air filters or policy-driven reductions in air pollution will improve clinical outcomes for patients with IPF. Such studies might 
involve randomised interventional trials of personal face masks, respirators or home-based air filters, while policy-based interventions would be more complex, typically involving administrative-level data to measure health outcomes in coding-based populations, before and after implemented changes. While changes in environmental policy are arguably the most effective to minimise harm to the largest number of individuals, they are also the most complex, impacted by juggernaut forces such as politics and economics. ${ }^{16}$ Furthermore, the challenge of identifying effective interventions in IPF has been well described and lies in the complexity and heterogeneity of the disease. Detecting a favourable effect from an environmental intervention may prove as challenging as from a pharmacological intervention, requiring large study cohorts and validated endpoints. In the absence of more robust data, it seems prudent for patients to follow regional recommendations for risk mitigation in order to minimise the impact of air pollution exposure, and consider themselves generally vulnerable to their inhaled environment.

Given the potential impact on clinical outcomes, further research on environmental exposures and IPF is warranted, from population-based epidemiology to interventional trials assessing the efficacy of masks or air filters to mitigate exposures and subsequent harm. Highlighting the importance of environmental health is as important now as ever, given the uncertain future face of air quality and climate change policy, ${ }^{16}$ and because of the unpredictable need to once again heed the warning that 'It's a real pea souper out there'.

Contributors KAJ wrote the manuscript and takes full responsibility for its content.

Competing interests KAJ reports personal fees and speakers' honoraria from Boehringer-Ingelheim and Hoffman La Roche, grants from the CHEST Foundation/ Pulmonary Fibrosis Foundation and UCB Pharma, outside of the submitted work.

Provenance and peer review Commissioned; externally peer reviewed.

(C) Article author(s) (or their employer(s) unless otherwise stated in the text of the article) 2018. All rights reserved. No commercial use is permitted unless otherwise expressly granted.

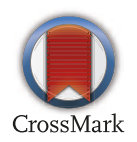

To cite Johannson KA. Thorax 2018;73:103-104.

Published Online First 3 November 2017

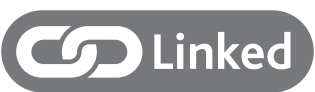

- http://dx.doi.org/10.1136/thoraxjnl-2017-209967

Thorax 2018;73:103-104.

doi:10.1136/thoraxjnl-2017-210808

\section{REFERENCES}

1 Ley B, Collard HR, King TE. Clinical course and prediction of survival in idiopathic pulmonary fibrosis. Am J Respir Crit Care Med 2011;183:431-40.

2 Turner MC, Jerrett M, Pope CA, et al. Long-term ozone exposure and mortality in a large prospective study. Am J Respir Crit Care Med 2016;193:1134-42.

3 Pope CA 3rd, Ezzati M, Dockery DW, et al. Fineparticulate air pollution and life expectancy in the United States. N Engl J Med 2009;360:376-86.
4 Pope CA, Turner MC, Burnett RT, et al. Relationships between fine particulate air pollution, cardiometabolic disorders, and cardiovascular mortality. Circ Res 2015;116:108-15.

5 Meng YY, Rull RP, Wilhelm M, et al. Outdoor air pollution and uncontrolled asthma in the San Joaquin Valley, California. J Epidemiol Community Health 2010;64:142-7.

6 Andersen ZJ, Bønnelykke K, Hvidberg M, et al. Long-term exposure to air pollution and asthma hospitalisations in older adults: a cohort study. Thorax 2012;67:6-11.

7 Schikowski T, Sugiri D, Ranft U, et al. Long-term air pollution exposure and living close to busy roads are associated with COPD in women. Respir Res 2005;6:152.

8 Dominici F, Peng RD, Bell ML, et al. Fine particulate air pollution and hospital admission for cardiovascular and respiratory diseases. JAMA 2006;295:1127-34.

9 Nawrot TS, Vos R, Jacobs $L$, et al. The impact of traffic air pollution on bronchiolitis obliterans syndrome and mortality after lung transplantation. Thorax 2011;66:748-54.

10 Jerrett M, Burnett RT, Beckerman BS, et al. Spatial analysis of air pollution and mortality in California. Am J Respir Crit Care Med 2013;188:593-9.

11 Raaschou-Nielsen 0, Andersen ZJ, Beelen R, et al. Air pollution and lung cancer incidence in 17 European cohorts: prospective analyses from the European Study of Cohorts for Air Pollution Effects (ESCAPE). Lancet Oncol 2013;14:813-22.

12 Johannson KA, Balmes JR, Collard HR. Air pollution exposure: a novel environmental risk factor for interstitial lung disease? Chest 2015;147:1161-7.

13 Sesé L, Nunes H, Cottin V, et al. Role of atmospheric pollution on the natural history of idiopathic pulmonary fibrosis. Thorax 2018;73:145-50.

14 Johannson KA, Vittinghoff E, Lee K, et al. Acute exacerbation of idiopathic pulmonary fibrosis associated with air pollution exposure. Eur Respir J 2014;43:1124-31.

15 Winterbottom CJ, Shah RJ, Patterson KC, et al. Exposure to ambient particulate matter is associated with accelerated functional decline in idiopathic pulmonary fibrosis. Chest 2017;3692:31391-0.

16 Hopkinson NS, Hart N, Jenkins G, et al. Climate change and lung health: the challenge for a new president. Thorax 2017;72:295-6. 